\title{
Asthma management in five European countries: doctors' knowledge, attitudes and prescribing behaviour
}

\author{
P. Lagerløv*, C.C.M. Veninga ${ }^{\#}$, M. Muskova ${ }^{+}$, E. Hummers-Pradier**, C. Stålsby Lundborg ${ }^{\S}$, \\ M. Andrew , F.M. Haaijer-Ruskamp ${ }^{++}$, on behalf of the Drug Education Project (DEP) group
}

\begin{abstract}
Asthma management in five European countries: doctors' knowledge, attitudes and prescribing behaviour. P. Lagerløv, C.C.M. Veninga, M. Muskova, E. Hummers-Pradier, C. Stalsby Lundborg, M. Andrew, F.M. Haaijer-Ruskamp, on behalf of the Drug Education Project (DEP) group. (C)ERS Journals Ltd 2000.

ABSTRACT: The aim of the study was to examine the relationship between guideline recommendations on asthma management, and the performance of doctors in five different European health care contexts. Knowledge, attitudes and prescribing behaviour of doctors recruited to an educational project was investigated.

A total of 698 general practitioners from Germany, the Netherlands, Norway and Sweden, and 94 specialists from the Slovak Republic participated. A questionnaire was used to assess their knowledge and attitudes. Antiasthmatic drugs dispensed to their patients reflected their prescribing behaviour.

In response to questions on how to treat chronic asthma, most doctors were in agreement with guideline recommendations. In practice, however, the proportion of asthma patients receiving inhaled steroids varied almost twofold, ranging $31 \%$ in Germany to $58 \%$ in the Netherlands. On questions related to exacerbation of asthma, German and Slovakian doctors often preferred treatment with antibiotics to steroids. They also more often associated yellow-green sputum with bacterial infection.

In conclusion, although many doctors in different health care contexts have accepted the recommendations given in guidelines, the proportion of their patients treated accordingly differed. German and Slovakian doctors seem to attach less importance to the inflammatory features of asthma than the doctors from the other three European countries.
\end{abstract}

Eur Respir J 2000; 15: 25-29.

Episodic cough, wheeze and breathlessness, may be reasons why asthma was perceived for many years as an episodic disorder of the airway smooth muscle. This concept propagated bronchodilators as a principal therapy for asthma [1]. Prescribing of inhaled steroids gradually increased during the 1980s [2], reflecting a growing understanding of asthma as an inflammatory disease, and this was incorporated into the guidelines developed by the British Thoracic Society (BTS) [3] in the early 1990s. Other European countries have adopted similar recommendations [4-9]. The key message is to control the underlying inflammatory condition with inhaled steroids, and the sudden worsening of the condition with oral steroids, rather than antibiotics. Despite a broad international consensus on the basic principles for treating asthma, different national health care systems, economies and medical tradition may influence the actual medical practice.

\begin{abstract}
* Dept of Pharmacotherapeutics, University of Oslo, Norway. "Northern Centre for Healthcare Research, University of Groningen, ${ }^{+}$Faculty of Pharmacy, Comenius University, Bratislava, **Dept of General Practice, University of Göttingen, ${ }^{5}$ Dept of Public Health Sciences, Division of International Health Care Research (IHCAR), Karolinska, Institutet, Stockholm. ${ }^{*}$ Norwegian Board of Health, Oslo, ${ }^{++}$Northern Centre for Healthcare Research, University of Groningen.
\end{abstract}

Correspondence: P. Lagerløv, Dept of Pharmacotherapeutics, University of Oslo, POB 1065 Blindern, N-0316 Oslo, Fax: 4722119013

Keywords: Asthma, attitudes, knowledge, prescribing

Received: December 291998

Accepted after revision August 301999

The project was financially supported by EU BIOMED I Programme (contract BMHI-CT93-1377), PECO NIS Programme (contract ERB-0CIPD-CT940231). Specific parts of the project were supported by the Dept of Health, Well-being and Sports in the Netherlands, the Research Fund for Social Pharmacy and Health Economics of the Apoteksbolaget in Sweden, the Norwegian Medical Association, the Norwegian Research Council, and the Norwegian Association of Proprietor Pharmacists, the German division of GlaxoWellcome

The aim of this study was to evaluate the relationship between knowledge, attitudes and prescribing behaviour of doctors from five European countries and the recommendations given in internationally accepted guidelines on asthma management.

\section{Material and methods}

Doctors within defined geographical areas in Germany, the Netherlands, Norway, the Slovak Republic and Sweden were invited to participate in the European Drug Education Project (DEP) to test the effect of education related to the diagnosis and treatment of urinary tract infection and asthma. After collecting the data presented here the doctors were randomized to receive small group education on either of the two diseases (in the Slovak Republic, asthma or no intervention) in two parallel studies, each of the

\footnotetext{
and Lilly Deutschland GmbH, the Ministry of Education in the Slovak Republic, and Foundation HN CLUB in the Slovak Republic.
} 
studies being a control group for the other. In the meetings the doctors discussed how to diagnose the disease and the underlying factors they judged important in deciding on the treatment. Guideline recommendations and prescribing feedback were also presented and discussed. The change in knowledge, attitudes and prescribing indicators from before to after the education and between groups of doctors in the two parallel studies was measured. The effect of the educational course is published elsewhere [10]. In the present part of the study the management of asthma was examined before the doctors received any guidelines from the DEP.

Recruitment in the different countries was as follows: Germany, Norway and the Slovak Republic, individual doctors; the Netherlands, entire local pharmacotherapycounselling groups; Sweden, groups of doctors working in the same health care centre. Three hundred and fifty-three doctors in Germany, 635 in Norway and 405 in the Slovak Republic were approached, of whom 32,31 and 23\%, respectively, agreed to participate. Twenty-five percent of the 98 invited groups in the Netherlands, and $35 \%$ of the 112 invited groups in Sweden participated. The doctors were general practitioners except in the Slovak Republic where they were specialists in pulmonary medicine or allergology.

Knowledge and attitudes were studied by using a questionnaire developed jointly by a group of general practitioners, specialists in pulmonary medicine and educationalists from the participating countries. Translation and back translation between English and the national languages was performed to ensure consistency of questions. Case histories with different treatment options were used to evaluate knowledge. The doctors responded by rating options provided as "correct", "incorrect" or "don't know". Attitudes were judged based on the doctors' extent of agreement to general statements on how to behave in specified clinical situations. The response to each question was rated according to the recommendations given by the BTS [3]. The proportion of correct answers was determined for each doctor. The questionnaire was divided in two parts, addressing: a) treatment of chronic asthma: the use of inhaled steroids in the stable chronic condition; b) exacerbation of asthma: the interpretation of signs and peak expiratory flow values, and the preference of using steroids or antibiotics in worsening of the asthmatic condition. The questionnaire was mailed to the participants, followed by two reminders if necessary. In Sweden the questionnaire was distributed during a meeting with the participants.

Antiasthmatics dispensed to the patients of each of the participating doctors were recorded at pharmacies (Norway, the Netherlands and Sweden), computerized databases of dispensing doctors (the Netherlands) or the sick funds (Germany, the Netherlands and the Slovak Republic). However, data were available for only 54/114 German doctors.

For the purpose of this study, an asthma patient was defined as a person aged 18-49 yrs who had received at least one antiasthmatic drug (Anatomical Therapeutic Chemical (ATC) classification system code R03 [11]) during the prescription collection period of 6 months (Norway, 12 months). The prescription collection in the different countries took place during 1994-1996. Anonymity of the patients was ensured throughout and after the study.
The prescribing behaviour of the doctors was studied by calculating the mean proportion of asthma patients receiving inhaled steroids, inhaled bronchodilators, oral bronchodilators, and xanthines per doctor per country.

A high dosage of one drug may often be a prerequisite for adding a second drug. Accordingly, two ratios were calculated: 1) the number of "high dose single users" of inhaled short-acting bronchodilators divided by all patients receiving inhaled short-acting bronchodilators per doctor. A "high dose single user" was defined as a patient receiving a dose of inhaled short-acting bronchodilators ( $\beta$ agonists or anticholinergics) averaging one inhalation or more per day during the data collection period, without in the same period using inhaled steroids or cromoglycates. One inhalation was in this study defined as one quarter of a defined daily dose (DDD) [11], corresponding to the amount of active substance in one metered dose of most bronchodilators; 2) the number of patients per country receiving inhaled long-acting $\beta$-agonists and low doses of inhaled steroids relative to the total number of patients receiving inhaled long-acting $\beta$-agonists. Low doses of inhaled steroids was defined as half a DDD, corresponding to $\leq 400 \mu \mathrm{g}$ of beclometasone [11], as a mean per day during the data collection period.

\section{Analysis}

Due to skewed distributions, the nonparametric MannWhitney 2-tailed test was used to examine differences in the questionnaire scores between countries. One way analysis of variance (ANOVA) was used to examine differences in prescribing between the countries. Bonferroni adjusted significance level was set to $<0.05$.

\section{Results}

Characteristics of the participating doctors are shown in table 1 . The mean age of the doctors did not differ from the national average of $45 \mathrm{yrs}$ in the Netherlands and 44 yrs in Norway. National data on age of doctors was not available in the other countries. Female doctors were slightly underrepresented in the Netherlands. In the other countries sex distribution did not differ from the national averages.

The mean scores on the knowledge- and attitude-questionnaire of the doctors from each country are given in table 2. The mean knowledge and attitudes scores on treatment of chronic asthma corresponded highly with the guideline recommendations, except for the mean score on knowledge among the Slovakian doctors. The mean scores on managing a sudden worsening of asthma were lower and showed wider variation between the countries. The mean scores of the Dutch and Swedish doctors were the highest, and the German and Slovakian doctors were the lowest. Most variation was seen in the response to the knowledge question on exacerbation of asthma: "Does yellow-green sputum always indicate a bacterial infection?" In the Netherlands $86 \%$, in Norway $44 \%$, in Sweden $41 \%$, in Germany $13 \%$ and in the Slovak Republic $4 \%$ correctly considered this statement incorrect.

The mean percentages of patients per doctor in each country receiving different types of asthmatic drugs are 
Table 1. - Characteristics of participating doctors

\begin{tabular}{lccccr}
\hline & $\begin{array}{c}\text { the } \\
\text { Netherlands }\end{array}$ & Norway & Germany & $\begin{array}{c}\text { the Slovak } \\
\text { Republic }\end{array}$ & Sweden \\
\hline Participating doctors n & 181 & 199 & 114 & 94 & 204 \\
Doctors responding to the questionnaire $n$ & $157(87)$ & $176(88)$ & $76(67)$ & $81(86)$ & $180(88)$ \\
Doctors with prescribing data n & $149(82)$ & $197(99)$ & $54(47)$ & $72(77)$ & $201(99)$ \\
Female doctors n & $22(12)$ & $45(23)$ & $23(20)$ & $59(63)$ & $84(41)$ \\
Mean age* & $46.7 \pm 6.8$ & $44.1 \pm 7.4$ & $48.1 \pm 8.5$ & $48.0 \pm 8.9$ & $45.7 \pm 5.9$ \\
\hline
\end{tabular}

Data are presented as absolute number with percentage in parentheses, except for the mean age which is presented as mean \pm SD. *: based on information from the questionnaire, calculated for the year of collecting prescribing data.

shown in table 3 . The total numbers of defined asthma patients among the participating doctors were as follows: Germany 291, the Netherlands 4,975, Norway 4,624, Slovakia 3,608 and Sweden 2,454. Inhaled steroids were dispensed to the highest proportion of asthma patients in the Netherlands. High dose single users of inhaled shortacting bronchodilators were slightly more common in the Netherlands than in Norway. In the other countries this indicator could not be reliably calculated. The proportion of asthma patients receiving short-acting inhaled bronchodilators was highest in Norway and Sweden and lowest in Germany. In Germany and the Slovak Republic xanthines and oral bronchodilators were more commonly used than in the other countries. The number of patients receiving long-acting inhaled $\beta$-agonists and low level of inhaled steroids $(<0.5 \mathrm{DDD}$ as a mean per day) relative to the total number of patients receiving long-acting inhaled $\beta$-agonists, varied $0.39-1.00$ between countries. In the Slovak Republic, long-acting inhaled $\beta$-agonists were not used during the data collection period. Of the asthma patients in the other countries $\leq 7.2 \%$ received inhaled long-acting $\beta$-agonists.

\section{Discussion}

Many doctors, who were to attend the educational intervention of the DEP study, held views corresponding to the guidelines recommendations, often agreeing to the use of inhaled steroids in treating chronic asthma. Guidelines for using inhaled steroids had not yet been introduced in the Slovak Republic at the time of the data collection, partly explaining why the specialists from the Slovak Republic appeared to have accepted this treatment to a lesser extent.
Contradictory views on asthma were better revealed by the questions on treatment of asthma when the condition suddenly worsens. The doctors from Germany and the Slovak Republic then often preferred to use antibiotics, and they more frequently associated yellow-green sputum with bacterial infection than the Dutch, Norwegian and Swedish doctors. This could indicate that many doctors still do not consider the inflammatory component of asthma to be of major importance.

Lack of agreement on the threshold of bronchodilator use before introducing anti-inflammatory treatment was reflected in the scoring of the questionnaire on treatment of chronic asthma. Two inhalations of bronchodilators or more per day were used as the threshold in the questionnaire. This is close to the Dutch guideline recommendations, but higher than in Norway and Sweden. The lower attitude scores on treatment of chronic asthma among the Dutch doctors, than among their Norwegian and Swedish colleagues, may thus be explained by their higher threshold for introducing inhaled steroids.

Some doctors will have a preference for advice from experienced doctors or experts while others will seek information in scientific publications or guidelines [12]. The Dutch doctors recruited from pharmacotherapy-counselling groups may have developed a culture of using guidelines more actively, thus explaining that their views were more often in agreement with the guideline recommendations. Low feasibility or acceptance of the recommendations may cause discrepancies between guideline recommendation and actual practice [13]. In an educational intervention on asthma it is thus important to explain the reason behind the recommendations, for instance explaining why, and not only how, to use antiinflammatory treatment.

Table 2. - Knowledge and attitudes to chronic asthma and exacerbation of asthma among doctors in each country shown as mean \pm SD scores giving the proportion of answers in agreement with guidelines

\begin{tabular}{lcccc}
\hline Country & $\begin{array}{c}\text { Knowledge } \\
\text { about treatment of } \\
\text { chronic asthma* }\end{array}$ & $\begin{array}{c}\text { Attitudes to treatment } \\
\text { of chronic asthma }\end{array}$ & $\begin{array}{c}\text { Knowledge of } \\
\text { exacerbation } \\
\text { of asthma }\end{array}$ & $\begin{array}{c}\text { Attitudes to treatment } \\
\text { of exacerbation }^{\#}\end{array}$ \\
\hline the Netherlands & $0.81 \pm 0.23$ & $0.94 \pm 0.18$ & $0.76 \pm 0.22$ & $0.83 \pm 0.25$ \\
Norway & $0.76 \pm 0.22$ & $0.97 \pm 0.13$ & $0.62 \pm 0.25$ & $0.70 \pm 0.34$ \\
Germany & $0.76 \pm 0.23$ & $0.81 \pm 0.28$ & $0.50 \pm 0.26$ & $0.42 \pm 0.32$ \\
the Slovak Republic & $0.66 \pm 0.23$ & $0.86 \pm 0.25$ & $0.47 \pm 0.21$ & $0.38 \pm 0.33$ \\
Sweden & $0.79 \pm 0.20$ & $1.00 \pm 0$ & $0.70 \pm 0.23$ & $0.73 \pm 0.31$ \\
\hline
\end{tabular}

*: the score in the Slovak Republic differs significantly from the scores in all countries but Germany; ${ }^{+}$: the score in Sweden differs significantly from those in the other countries. The score in Norway differs significantly from the scores in Germany, the Slovak Republic and Sweden. The score in the Netherlands differs significantly from the score in Germany and Sweden; ${ }^{*}$ : the scores in the Netherlands and Sweden differ significantly from those in the other countries. The score in Norway differs significantly from the scores in the other countries. Mann-Whitney 2-tailed test (Bonferroni adjusted $\mathrm{p}<0.05$ ). 
Table 3. - Prescribing behaviour

\begin{tabular}{lccccc}
\hline & $\begin{array}{c}\text { Patients } \\
\text { receiving IS** } \\
\%(95 \% \text { CI })\end{array}$ & $\begin{array}{c}\text { Patients receiving } \\
\text { high-dose* IBD without } \\
\text { anti-inflammatory treatment } \\
\%(95 \% \text { CI })\end{array}$ & $\begin{array}{c}\text { Patients } \\
\text { receiving IBD } \\
\%(95 \% \text { CI) }\end{array}$ & $\begin{array}{c}\text { Patients } \\
\text { receiving OBD } \\
\%(95 \% \text { CI) }\end{array}$ & $\begin{array}{c}\text { Patients } \\
\text { receiving xan } \\
\%(95 \% \text { CI) }\end{array}$ \\
\hline the Netherlands & $58.0(55.6-60.4)$ & $27.9(25.4-30.3)$ & $71.3(69.2-73.3)$ & $3.5(2.1-5.0)$ & $2.2(1.6-2.8)$ \\
Norway & $45.9(43.9-48.0)$ & $23.8(21.9-25.8)$ & $82.6(81.0-84.2)$ & $3.7(3.0-4.5)$ & $6.4(5.3-7.5)$ \\
Germany & $30.8(22.6-38.9)$ & ND & $34.0(26.2-41.9)$ & $16.8(11.0-22.7)$ & $24.9(17.0-32.7)$ \\
the Slovak Republic & $39.2(35.4-43.0)$ & ND & $67.0(63.6-70.4)$ & $12.0(9.2-14.8)$ & $45.6(41.6-49.7)$ \\
Sweden & $45.1(42.3-47.8)$ & ND & $78.7(76.3-81.0)$ & $4.2(3.3-5.2)$ & $2.6(1.3-3.8)$ \\
\hline
\end{tabular}

Data are presented per doctor in each country and relative to all defined asthma patients, except for patients receiving high doses of inhaled bronchodilators (IBD), where data are relative to all patients receiving IBD. *: defined as one inhaled metered dose (equal to 0.25 defined daily dose) or more as a mean per day. ${ }^{*}$ : the mean percentages differ significantly except between Norway and Sweden, between Sweden and the Slovak Republic and between the Slovak Republic and Germany. ${ }^{\#}$ : the mean percentages differ significantly. t: the mean percentage differ significantly except between Norway and Sweden and between the Netherlands and the Slovak Republic. : the mean percentages in Germany and the Slovak Republic differ significantly from the mean percentages in the other countries. ${ }^{\# \#}$ : the mean percentages differ significantly from those in the other countries but not between the Netherlands and Sweden. One way ANOVA, Bonferroni adjusted p<0.05. IS: inhaled steroids; OBD: oral bronchodilators; xan: xanthines; CI: confidence interval. ND: no data.

Although knowledge and attitudes scores on treatment of chronic asthma were uniformly high, the proportion of patients dispensed inhaled steroids per doctor in each of the five European countries differed. Prescribing patterns in Europe are known to vary widely between countries [14] and this is attributed to deep-rooted variations in medical culture and training [15]. In this study, the prescribing of inhaled steroids and the knowledge and attitudes among the doctors in each country appeared to be related. However, in Germany the use of inhaled steroids was noticeably low. One relevant factor may be the German reimbursement system setting budget limits for prescribing expenditure per doctor. Efforts to reduce prescribing cost may tend to lower the use of inhaled steroids [16], which are relatively expensive drugs. Some of the differences in the proportions of patients receiving inhaled steroids between countries may furthermore be related to variation on asthma severity. The prevalence of nocturnal attacks of breathlessness as a sign of severity has been shown to correlate positively with the use of oral and inhaled anti-inflammatory treatments [17].

A somewhat higher proportion of patients in the Netherlands used inhaled bronchodilators daily without any antiinflammatory treatment as compared to patients in Norway. This may be partly explained by differences in the recommended thresholds for introducing inhaled steroids in the two countries. Not all prescribed drugs are collected at the pharmacies by the patients [18], and so patient decisions could thus partly explain this non-use of antiinflammatory treatment. Data from Denmark confirms a similar situation of high dose use of bronchodilators as a single medication [19].

A preference for oral treatment in Eastern and Southern Europe has been described [20] and may be a barrier to choosing inhaled anti-inflammatory treatment. A predilection for oral therapy may also be a consequence of perceiving asthma as a disease not only confined to the airways, but affecting the whole body.

In this study long-acting $\beta$-agonists were commonly dispensed alone or in combination with lower doses of inhaled steroids than recommended in guidelines at the time of the study. This discrepancy with guideline recommendations may not necessarily indicate poor practice. The recent updated guidelines from the BTS now recommend a lower threshold of inhaled steroids for introducing longacting inhaled $\beta$-agonists [21]. However, adequate antiinflammatory treatments are considered a prerequisite for the safe use of long-acting $\beta$-agonists [22].

The results in this study reflect the knowledge, attitudes and prescribing behaviour of doctors willing to participate in an educational programme. This has most likely introduced a selection bias. The participation rates for doctors or groups in each country are, however, at the same level and should permit an inter-country comparison of the participating doctors' performance. The prescribing behaviour of the German doctors should be interpreted with some caution since few of the doctors supplied prescription data.

\section{Conclusions}

Most doctors recruited to this study from different health care systems agreed to new principles for the management of chronic asthma using inhaled steroids. However, the proportion of their patients actually treated with inhaled steroids differed to a large extent. In addition their knowledge and attitudes related to exacerbation of asthma indicate a lack of acknowledgement of the inflammatory component of the disease. In educational interventions, like the Drug Educational Project study, barriers for change need to be identified. Differences in perceptions of the disease, in the confidence in experts or guidelines, in the reimbursement systems and differences in patients' preferences may give distinct barriers of such programme between countries to improving asthma management.

\footnotetext{
Acknowledgements. The authors thank all doctors and pharmacists who participated in this project, and P. Hjortdahl, Dept of General Practice, Oslo, for support and guidance in writing the manuscript. For supplying prescribing data the authors thank the health insurance companies "Het Groene Land" and "RZG" in the Netherlands, "VSZP" in the Slovak Republic, "AOK Niedersachsen" in Germany, the Apoteksbolaget in Sweden, and the participating Norwegian pharmacies.
} 
The Drug Education Project (DEP)-group. International coordinator F.M. Haaijer-Ruskamp (the Netherlands). The Netherlands: P. Denig, C.C.M. Veninga; Sweden: V. Divan, G. Thomson, R. Wahlström, T. Oke, and C. Stalsby Lundborg; Norway: M. Andrew, M. Loeb, P. Lagerløv, the late I. Matheson; Germany: M.M. Kochen, E. Hummers-Pradier; Slovak Republic: M. Muskova, Z. Kopernicka.

\section{References}

1. Holgate ST. The cellular and mediator basis of asthma in relation tonatural history. Lancet 1997; 350 (Suppl. II): $5-9$.

2. Kemp JP. Approaches to Asthma Management. Realities and Recommendations. Arch Intern Med 1993; 153: 805812.

3. British Thoracic Society, British Paediatric Association, Royal College of Physicians, King's Fund Centre, National Asthma Campaign, Royal College of General Practitioners, General Practitioners in Asthma Group, British Association of Accident and Emergency Medicine, British Paediatric Respiratory Group. Guidelines on the management of asthma. Thorax 1993; 48: S1-24.

4. Bottema BJAM, Fabels EJ, Van Grusven PM, et al. Dutch College of General Practitioners - Guideline Adults with Chronic Non-specific Lung Diseases; Diagnosis. Huisarts Wet 1992; 35: 430-436.

5. Van der Waart MAC, Dekker FW, Nijhoff S, et al. Dutch College of General Practitioners - Guideline Adults with Chronic Non-specific Lung Diseases; Treatment. Huisarts Wet 1992; 35: 437-443.

6. Norwegian Drug and Therapeutic Formulary 1994-95. Vennerød Am, ed. Oslo, Norsk Legemiddelhåndbok I/S, 1994; pp. 469-482.

7. Wettengel R, Berdel D, Cegla U, et al. Recommendation of the German Respiratory Tract League on asthma management of adults and children. The German Respiratory Tract League. Med Klin 1994; 15; 89(2): 57-67.
8. Kristufec P, Hruskovic I. National guidelines for optimal diagnosis and management of asthma in Slovak republic. The Slovak Medical Society in Bratislava, Slovakia 1996.

9. Medical Products Agency. Workshop: Pharmacological Treatment of Bronchial Asthma (1993:1). Uppsala, Medical Products Agency, 1993.

10. Veninga CCM, Lagerløv P, Wahlstrøm R, et al. Evaluating an educational intervention to improve the treatment of asthma in four European countries. Am J Respir Crit Care Med 1999; 160: 1254-1262.

11. Guidelines for ATC classification and DDD assignment. Oslo: WHO Collaboration Centre for Drug Statistics Methodology, 1994.

12. Marshall T. Scientific knowledge in medicine: a new clinical epistemology? JEval Clin Pract 1997; 3: 133-138.

13. Jans MP, Shellevis FG, Van Hensbergen W, Van Emden TD, Van Eijk JTM. Management of asthma and COPD patients: feasibility of the application of guidelines in general practice. Int J Qual Health Care 1998; 10: 27-34.

14. Kimbel KH. Drug prescribing patterns in Europe. Int $J$ Clin Pharmacol Ther Toxicol 1992; 30: 459-461.

15. Taylor D. Prescribing in Europe-forces for change. $B M J$ 1992; 304: 239-242.

16. Naish J, Sturdy P, Toon P. Appropriate prescribing in asthma and its related cost in east London. BMJ 1995; 310: 97-100.

17. Janson C, Chinn S, Javis PB. Physician-diagnosed asthma and drug utilization in the European Community Respiratory Health Survey. Eur Respir J 1997; 10: 1795-1802.

18. Nilsson JL, Johansson H, Wennberg M. Large differences between prescribed and dispensed medicine could indicate undertreatment. Drug Information J 1995; 25: 1243-1246.

19. Hallas J, Hansen N-C G. Individual utilization of antiasthma medication by young adults: a prescription database analysis. J Intern Med 1993; 234: 65-70.

20. Vermeire P. Difference in asthma management around the world. Eur Respir Rev 1994; 4: 21, 279-281.

21. Keeley D, Rees J. New guidelines on asthma management. BMJ 1997; 314: 315-316.

22. Bone RC. Another word of caution regarding a new longacting bronchodilator. JAMA 1995; 273: 967-968. 